\title{
Design of a hybrid carbon fibre/carbon nanotube composite for enhanced lightning strike resistance
}

\author{
Xiang Ma ${ }^{1}$, Fabrizio Scarpa ${ }^{1,2 *}$, Hua-Xin Peng ${ }^{3}$, Giuliano Allegri ${ }^{1,4}$, Jie Yuan $^{1,2}$, Romeo Ciobanu ${ }^{5}$ \\ ${ }^{1}$ Department of Aerospace Engineering, Queens School of Engineering, University of Bristol, Bristol, UK \\ ${ }^{2}$ Advanced Composites Centre for Innovation and Science (ACCIS), Queens School of Engineering, University of \\ Bristol, BS8 1TR Bristol, UK \\ ${ }^{3}$ Institute for Composites Science Innovation, School of Materials Science and Engineering, Zhejiang University, \\ Hangzhou, 310027, PR China \\ ${ }^{4}$ Department of Aerospace Engineering, Imperial College, London, UK \\ ${ }^{5}$ Department of Electrical Measurements and Materials, Technical University "Gh. Asachi”, Iasi, Romania
}

\begin{abstract}
This work presents a set of analytical design models to predict the electrical and mechanical properties of hybrid carbon nanotubes (CNT)/carbon-fibre (CF)/epoxy composites for potential use in fuselage and airframe constructions against lightning strike. The models are validated by experimental data from open literature. An optimization process is carried out to identify the microstructural configuration of the composite that provides the highest improvement in terms of electrical conductivity for the lowest structural weight in a CFRP fuselage design. The through-the-thickness conductivity of the composite laminate is considerably enhanced by a $2 \%$ volume fraction dispersion of CNTs within the matrix resin. The increase in the dielectric properties is accompanied by a moderate improvement of the composite mechanical performance. The hybrid CFRP/CNT composite configuration leads to a weight-efficient design solution for representative fuselage structures.
\end{abstract}

Keywords: lightning strike protection, carbon fibre composite, carbon nanotube, fuselage panel, design, optmisation

*Corresponding Author: Fabrizio Scarpa, Advanced Composites Centre for Innovation and Science (ACCIS), University of Bristol, BS8 1TR Bristol, UK. Email: f.scarpa@bristol.ac.uk 


\section{Nomenclature}

$\sigma_{C}$

б0

${ }^{\sigma} m$

$\sigma_{1}$

$\eta$

f

$f_{c}$

$f_{C F}$

$t$

$p$

$H(p)$

$\xi$

$E_{L}$

$E_{T}$

$E_{m}$

$E_{f}$

$v_{12}$

X

$X_{f}$

$X_{m}$

$\sigma_{c x}$

$\hat{\sigma}_{m}$

$f^{\prime}{ }_{C F}$

$f_{C F}$

$P$

$\sigma_{x}$

$L$

A

Effective conductivity of the nanocomposite [S/m]

Conductivity of the nanocomposite (base constant) $[\mathrm{S} / \mathrm{m}]$

Electrical conductivity of the polymer matrix $[\mathrm{S} / \mathrm{m}]$

Axial electrical conductivity of the CNTs [S/m]

Waviness of the nanotubes

Volume fraction of the nanotubes

Critical volume fraction of the nanotubes

Volume fraction of the carbon fibres

Constant

Aspect ratio of carbon nanotubes

Principal depolarization factor for the percolation

Volume fraction of percolated MWCNts in the nanocomposite

Longitudinal Young's modulus of the nanocomposite [Pa]

Transverse Young's modulus of the nanocomposite $[\mathrm{Pa}]$

Young's modulus of the matrix [Pa]

Young's modulus of the CNT [Pa]

Poisson's ratio of the nanocomposite

Strength of the nanocomposite $[\mathrm{Pa}]$

Strength of the nanotube [Pa]

Strength of the matrix $[\mathrm{Pa}]$

Ultimate strength of the composite [Pa]

Stress at matrix failure $[\mathrm{Pa}]$

effective fiber volume fraction given as $f_{C F}(1-P)$

fiber volume fraction

degradation parameter $(0 \leq P \leq 1)$;

Overall conductivity in longitudinal direction $[\mathrm{S} / \mathrm{m}]$

Fuselage length

Cross-section area of fuselage skin $\left[\mathrm{m}^{2}\right]$ 


$\begin{array}{ll}C & \text { Fuselage circumference }[\mathrm{m}] \\ t_{s} & \text { Fuselage skin [m] } \\ t_{p} & \text { Thickness of a single ply [m] } \\ \rho_{n} & \text { Density of the carbon fibres }\left[\mathrm{kgm}^{-3}\right] \\ \rho_{m} & \text { Density of the pristine matrix }\left[\mathrm{kgm}^{-3}\right] \\ \rho_{c n} & \text { Density of the carbon nanotubes }\left[\mathrm{kgm}^{-3}\right] \\ p & \text { Pressurisation (pressure) }[\mathrm{Pa}] \\ O b j & \text { Original objective function } \\ O b j^{*} & \text { Scaled objective function } \\ S_{L} & \text { Lower boundary of design space } \\ S_{H} & \text { Upper boundary of design space }\end{array}$




\section{Introduction}

Protection against lightning strike is a particularly important aspect of modern airframe design. Lightning is caused by the electrical discharge between the cumulonimbus and the ground. Existing studies describe the lightning process via three possible modes of charge transfer [1]: (a) Dart-leader-return-stroke sequences (represented by wave A in Figure 1), (b) continuing currents (represented by wave B and C in Figure 1), and (c) M-components (represented by wave D in Figure 1). Two types of lightning (positive and negative) are observed in nature according to their electric polarisation. The current of a negative lightning is on average between $30 \mathrm{kA}$ and $50 \mathrm{kA}$ [1], while the positive lightning could induce a current as high as 200kA [2]. In spite of the fact that only $10 \%$ of a lightning transfers a positive charge [1], a positive lightning strike can have considerably more severe consequences than a negative one. The SAE ARP 5412 code [3] standardizes lightning current waveforms to perform simulations and tests and evaluate the effects of lightning on aircrafts. As it can be observed in Figure 1, the lightning current consists of four components, denoted as A to D. Wave A represents the first return stroke peak of the current during the first $0.5 \mu \mathrm{s}$. Waveforms $\mathrm{B}$ and $\mathrm{C}$ represent the current following the first stroke peak, and act as a bridge connecting the wave $\mathrm{A}$ and the last waveform $\mathrm{D}$, which represents a subsequent restrike. The amplitudes of waveforms $\mathrm{B}$ and $\mathrm{C}$ are much lower than those of $\mathrm{A}$ and $\mathrm{D}$, although they have a relatively longer duration (up to 1 second). All the essential characteristics of the current waveforms are summarized in Table 1. Lightning currents are usually expressed in exponential forms for some modelling and design purposes.

Metal airframes of typical civil aircraft act as Faraday cages, therefore protecting the aircraft systems, the crew and the passengers against lightning strike. Carbon fibre reinforced plastics (CFRP) is one of the most popular class of materials for modern composite aircrafts, and the use of CFRP in airframes has led to significant weight saving. However, protection against lighting strike represents a considerable issue for the successful implementation of composite-based airframe constructions [4], because both CFRPs and the paint at the surface are non-conductive, therefore a composite airframe does not behave as a Faraday cage anymore [5]. State-of-the-art protection technologies against lightning strike include the integration of copper meshes within the CFRP structures and the use of conductive coatings. Conductive metal material may be added either between composite laminates, or to the surface of the airframe skin [6]. The use of embedding metal meshes or metal additives provide an adequate lightning strike protection to CFRP structures but also have significant drawbacks, such as an increase in structural weight and a general decrease of the mechanical properties versus the ones of the pristine composite material configuration, in particular for the interlaminar strength [6]. For a typical civil aircraft design the use of a surface copper mesh would imply the increase of the total mass of the plane by a couple hundred of kilograms on average. Thermal residual stresses between the copper wires and the CFRP plies also reduce the fatigue endurance of composites $[3,7]$. It is clear that a significant increase of the conductivity of CFRPs would enable a significant reduction of the weight of the embedded conductive meshes and the coating.

Carbon nanotubes (CNT) exhibit an excellent range of multiphysics properties both in terms of electrical conductivity and mechanical stiffness, with current density around of $109 \mathrm{~A} / \mathrm{cm}^{2}$ and Young's modulus between 1.0 TPa and 1.4TPa [8]. The use of CNTs dispersed in thermoset resins to improve stiffness, strength and dielectric properties has been evaluated by a considerable number of researchers [9] . Recently, Lockheed Martin has also started to introduce a CNT-reinforced thermoset matrix to produce the F-35 wingtip fairings [10], and paints based either on epoxy or thermoplastic resin with CNTs have been patented for lightning strike protection in aircraft [11]. CNT-reinforced nanocomposites also show a 
strain-dependent loss factor under harmonic loading and their use as a possible surrogate to constrained layer damping treatments in surface controls of business-type aircrafts has been evaluated by some of the Authors [12].

This paper describes the development of a methodology within a multiobjective optimisation framework to perform the preliminary design of laminates with carbon-nanotube doped resin for their use in composite fuselage applications. The design is performed to identify the content of nanotubes, carbon fibre, number of plies and ply thickness to maximise the in-plane and through-the-thickness electric resistance of the panel and minimise the surface mass. The aircraft fuselage is represented by a simplified cylindrical model to calculate both the resistance and the hoop and longitudinal stresses, the latter being used to verify mechanical stiffness and failure requirements.

The current design philosophy to preserve the in-service structural integrity of aerospace composites is based on a "damage tolerant" approach. This is underpinned by a "no growth" requirement for delaminations [13]. Hence, strains must be low enough to avoid propagation of barely visible damage for the entire service life of a composite airframe. A representative limit of the in-plane principal strain for "no growth" is $4000 \mu \varepsilon$ at ultimate load, i.e. $2700 \mu \varepsilon$ at limit load [13]. These values are dictated by the post-impact or "notched" material properties of composites, such as compression after impact (CAI) and open-hole tension/compression. The "no growth" design approach is substantiated by extensive experimental characterisations carried out according to the "pyramid of testing" approach [13]. The adoption of the "no growth" criterion is due to the uncertainties associated with the static, fatigue and impact behaviour of FRPs, particularly in presence of variable temperature and moisture content. However, "no growth" strain limits correspond to less than a third of the pristine static strength of FRPs [14]. The effect of fatigue on the in-plane strength of FRPs is much less significant than for alloys, also in presence of stress concentrations [13].

In the proposed design methodology a linear electric conductance model approximates the in-plane and through-the-thickness resistance. Modelling the effect of lightning strike on composite structures requires in general to solve a complex electrical-thermal problem [15]. The low through-thickness conductivity of fibre-reinforced polymers subject to lightning strike induces localized heating due to eddy currents. The amount of heating is sufficient for the pyrolysis of the composite to take place. This phenomenon is further exacerbated by the presence of shock waves having magnitude in the order to tens of MPa, which promote the onset and propagation of delaminations. Pyrolysis may cause localized puncture of the composite structures, which, in the case of a fuselage, may lead to catastrophic decompression. Capturing the complex physics associated with the impingement of lightning strikes on composite structures and the associated thermo-electro-mechanical interactions is beyond the scope of this paper. Here, the conductivity of the material is used as a proxy for evaluating the improvement of lightning strike resistance, under the assumption that the Joule heating due to eddy currents governs the resulting damage in the composite material. 


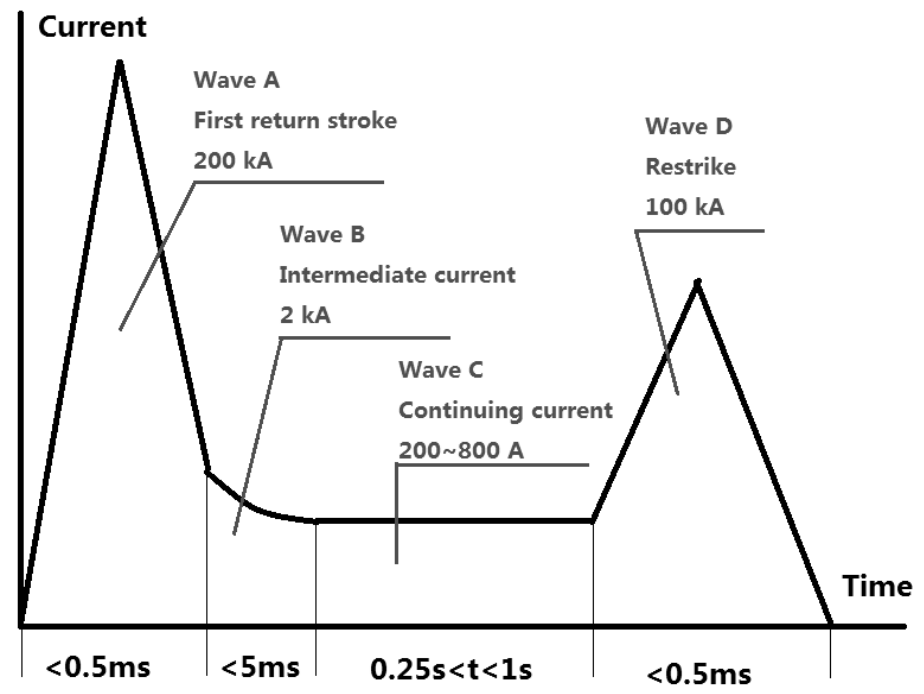

Figure 1 Simulated lightning current waveform recommended by SAE [16]

Table 1 Parameters for lightning current waveform [17]

\begin{tabular}{|c|c|c|c|c|c|}
\hline \multicolumn{2}{|c|}{$\begin{array}{c}\text { Wave } \\
\text { Components }\end{array}$} & $A$ & $B$ & C & $D$ \\
\hline \multicolumn{2}{|c|}{ Peak Amplitude } & $200 \mathrm{kA}( \pm 10 \%)$ & $2 \mathrm{kA}( \pm 10 \%)$ & $200 \mathrm{~A}$ & $100 \mathrm{kA}( \pm 10 \%)$ \\
\hline \multicolumn{2}{|c|}{$\begin{array}{l}\text { Action Integral } \\
\quad\left(\int \mathrm{i}^{2}(\mathrm{t}) \mathrm{dt}\right)\end{array}$} & $2 \times 10^{6} \mathrm{~A}^{2} \mathrm{~s}$ & - & - & $0.25 \times 10^{6} \mathrm{~A}^{2} \mathrm{~s}$ \\
\hline \multicolumn{2}{|c|}{ Peak Rate of Rise } & $1 \times 10^{11} \mathrm{~A} / \mathrm{s}$ & - & - & $0.5 \times 10^{11} \mathrm{~A} / \mathrm{s}$ \\
\hline \multicolumn{2}{|c|}{ Duration } & $\leq 500 \mu \mathrm{s}$ & $\leqslant 5 \mathrm{~ms}$ & $\approx 1 \mathrm{sec}$ & $\leqslant 500 \mu \mathrm{s}$ \\
\hline \multirow{4}{*}{$\begin{array}{l}\text { Analytica } \\
1 \text { model }\end{array}$} & $i(t)$ & \multicolumn{2}{|c|}{$i(t)=I_{0}\left(e^{-\alpha t}-e^{-\beta t}\right)$} & 200(const.) & $i(t)=I_{0}\left(e^{-\alpha t}-e^{-\beta t}\right)$ \\
\hline & $\mathrm{I}_{0}$ & $223,000(\mathrm{~A})$ & $11,300(\mathrm{~A})$ & - & $130,000(\mathrm{~A})$ \\
\hline & a & $11,000\left(\mathrm{~s}^{-1}\right)$ & $700\left(s^{-1}\right)$ & - & $27,500\left(\mathrm{~s}^{-1}\right)$ \\
\hline & $\beta$ & $460,000\left(s^{-1}\right)$ & $2000\left(\mathrm{~s}^{-1}\right)$ & - & $415,000\left(\mathrm{~s}^{-1}\right)$ \\
\hline
\end{tabular}




\section{Materials and models}

\section{Constituents of the nanotube composite}

Two types of carbon nanotubes are considered in this study (Table 2), namely single- and multi-walled. Single-walled nanotubes possess both higher stiffness and electrical conductivity, while the multi-walled nanotubes (MWCNTs) have a significantly lower cost compared to SWCNTs (about 1/200). In view of a potential industrial-scale use and in order to reduce the capital costs involved, multi-walled nanotubes are considered in this work.

Table 2 Properties of SWNT and MWNT (*[18]** [19]*** [20])

\begin{tabular}{r|cc}
\hline CNT species & $S W N T$ & $M W N T$ \\
\hline Density $\left(\mathrm{kg} / \mathrm{m}^{3}\right)$ & $140^{*}$ & $280^{*}$ \\
Inner Diameter $(\mathrm{nm})$ & $0.8 \sim 1.6^{*}$ & $5 \sim 10^{*}$ \\
Outer diameter $(\mathrm{nm})$ & $1 \sim 2^{*}$ & $20 \sim 30^{*}$ \\
Length $(\mu \mathrm{m})$ & $3 \sim 30^{*}$ & $3 \sim 30^{*}$ \\
Aspect Ratio & $100 \sim 10,000^{* *}$ & $100 \sim 10,000^{* *}$ \\
Tensile Modulus $(\mathrm{GPa})$ & $1500^{* *}$ & $1000^{* *}$ \\
Tensile Strength $(\mathrm{GPa})$ & $50 \sim 500^{* *}$ & $10 \sim 60^{* *}$ \\
Poisson's ratio & $0.34^{* * *}$ & $0.2^{* * * *}$ \\
Electrical conductivity $(\mathrm{S} / \mathrm{m})$ & $1 \times 10^{5} \sim 1 \times 10^{6 * *}$ & $5 \times 10^{4} \sim 1 \times 10^{6 * *}$ \\
Thermal Conductivity $(\mathrm{W} / \mathrm{m}-$ & $3,000 \sim 6,000^{* * *}$ & $3,000 \sim 6,000^{* *}$ \\
$\mathrm{~K})$ & & \\
Price $(\mathrm{USD} / \mathrm{kg})$ & $25,000^{*}$ & $700^{*}$ \\
\hline
\end{tabular}

Epoxy ER2074 has been selected as the polymer matrix for the case study, with its typical properties shown in Table 3 [21]. The carbon fibres selected are IM7 and T300 (Table 4) IM7 has better mechanical properties (modulus and strength) compared to T300, but the opposite is true for the dielectric performance. The thermal conductivity of T300 is about twice that of IM7. The T300 fibre also exhibits a slightly higher specific heat and resistivity. These facts imply that although a T300 composite would experience a lower temperature increase at constant current levels, a larger volume fraction of T300 fibre would be needed to obtain the same stiffness and strength compared to IM7. In this study the IM7 carbon fiber has been chosen because of its current widespread use in the airframe of modern civil airliners (A350XWB and Boeing 787).

Table 3 Properties of epoxy resin [21]

\begin{tabular}{r|c}
\hline & Epoxy ER2074 \\
\hline Young's modulus (GPa) & 3.3 \\
Poisson's ratio & 0.48 \\
Shear modulus (GPa) & 1.11 \\
\hline
\end{tabular}




\begin{tabular}{r|c}
\hline Cured density $\left(\mathrm{kg} / \mathrm{m}^{3}\right)$ & 2090 \\
Volume resistivity $(\Omega-\mathrm{cm})$ & $1 \times 10^{15}$ \\
Electrical conductivity $(\mathrm{S} / \mathrm{m})$ & $1 \times 10^{-13}$ \\
Tensile strength $(\mathrm{MPa})$ & 72 \\
Strain at break & $0.30 \%$ \\
Compressive strength $(\mathrm{MPa})$ & 102 \\
shear strength $(\mathrm{MPa})$ & 34 \\
specific heat @ 297K $(\mathrm{J} / \mathrm{kg}-$ & $1.08 \mathrm{E}+03$ \\
$\mathrm{~K})$ & \\
\hline
\end{tabular}

Table 4 Properties of carbon fiber candidates [22, 23]

\begin{tabular}{c|cc}
\hline Carbon fiber tow & HexTow IM7 & TORAYCA \\
& & T300 \\
\hline Density $\left(\mathrm{kg} / \mathrm{m}^{3}\right)$ & 1770 & 1760 \\
Tensile modulus $(\mathrm{GPa})$ & 270 & 230 \\
Poisson's ratio & 0.3 & 0.3 \\
Shear modulus $(\mathrm{GPa})$ & 5 & 5 \\
Tensile strength $(\mathrm{MPa})$ & 5670 & 3530 \\
Shear strength $(\mathrm{MPa})$ & 36 & - \\
Failure elongation & $1.80 \%$ & $1.50 \%$ \\
Electrical resistivity $(\Omega / \mathrm{cm})$ & $1.5 \times 10^{-3}$ & $1.7 \times 10^{-3}$ \\
Thermal conductivity $(\mathrm{W} / \mathrm{m}$ & 5.40 & 10.64 \\
K) & & \\
Specific heat $(\mathrm{J} / \mathrm{kg} \mathrm{K})$ & 710 & 795 \\
\hline
\end{tabular}

\section{Dielectric models of the equivalent matrix}

A self-consistent scheme [24] is used to predict the effective properties of the CF/CNT/polymer laminate. This scheme is based on a three-phase model, in which a single type inclusion is firstly embedded in the finite matrix material region, then the other phase is integrated into this effective matrix by using existing rules of mixtures. The model can be adopted by assuming that the carbon fibres are in a woven topology and they are cured into an effective continuum polymer matrix with the CNT dispersions. This assumption is reasonable because the dimensions of the carbon nanotubes are several orders of magnitude smaller than the carbon fibres. The CNTs are also assumed to be uniformly distributed within the polymer matrix. Using this analytical multiscale approach, the number of phases in the final composite is reduced to two, thus leading to a simplified model. The input variables of the model include the volume fractions of all the constituents, their multiphysics characteristics (electrical and mechanical properties), and the thicknesses and stacking sequence of the resulting laminate. The model is able to predict the electrical and mechanical properties of the resulting system, including the electrical conductivity in three dimensions and the mechanical strength and stiffness.

The mechanical properties of the effective matrix (epoxy/carbon nanotubes) are evaluated in this work using different homogenization theories. The weight fraction of the nanotubes is constrained to be lower than a maximum threshold, to avoid increased viscosity and clustering of the nanoparticles. The percolation of the carbon nanotubes is an essential aspect determing the conductivity of the 
nanocomposites. Existing studies have investigated the percolation in conductive and semi-conductive composites $[25,26]$. In a system which is constituted of conductive and nonconductive materials, when the loading of the conductive material reaches some threshold (percolation limit), the conductivity of the whole system will increase dramatically by several order of magnitude, due to the formation of conductive networks [26]. Two models to predict the effective conductivity of the carbon nanocomposite are here considered. The first is a power law, which is the most widely applied scheme in the open literature and fits well experimental data [27-29]. The second approach is the analytical model proposed by Deng and Zheng [30], which takes into account geometric parameters including the aspect ratio and the waviness of the nanotubes. The two models are recalled in Appendix A.

Several data sets about the electrical conductivities of MWNT/nonconductive matrix composites have been collected from open literature and plotted in Figure 2, in order to identify average values of the exponent of the power law and the reference conductivity $\sigma_{0}$. Apart from the data set \#2, it is apparent that the percolation thresholds are around a 0.7 vol\% value. Below this volume fraction, the conductivity of the MWNT composite is less than $10^{-10} \mathrm{~S} / \mathrm{m}$. Above this percolation level, the conductivity increases up to 10 orders of magnitude. A least squares fit of the power law to the observed data provides a value of $\sigma_{0}=1000 \mathrm{~S} / \mathrm{m}$ and $t=2$ have been found to give a relatively typical trend of the observed data. In practice, the percolation threshold depends upon several other factors, including geometry, the processing methods and the matrices used [31]. The orientation of nanotubes also has significant effects, as shown by the data set \#2 for an aligned MWNT/epoxy composite.

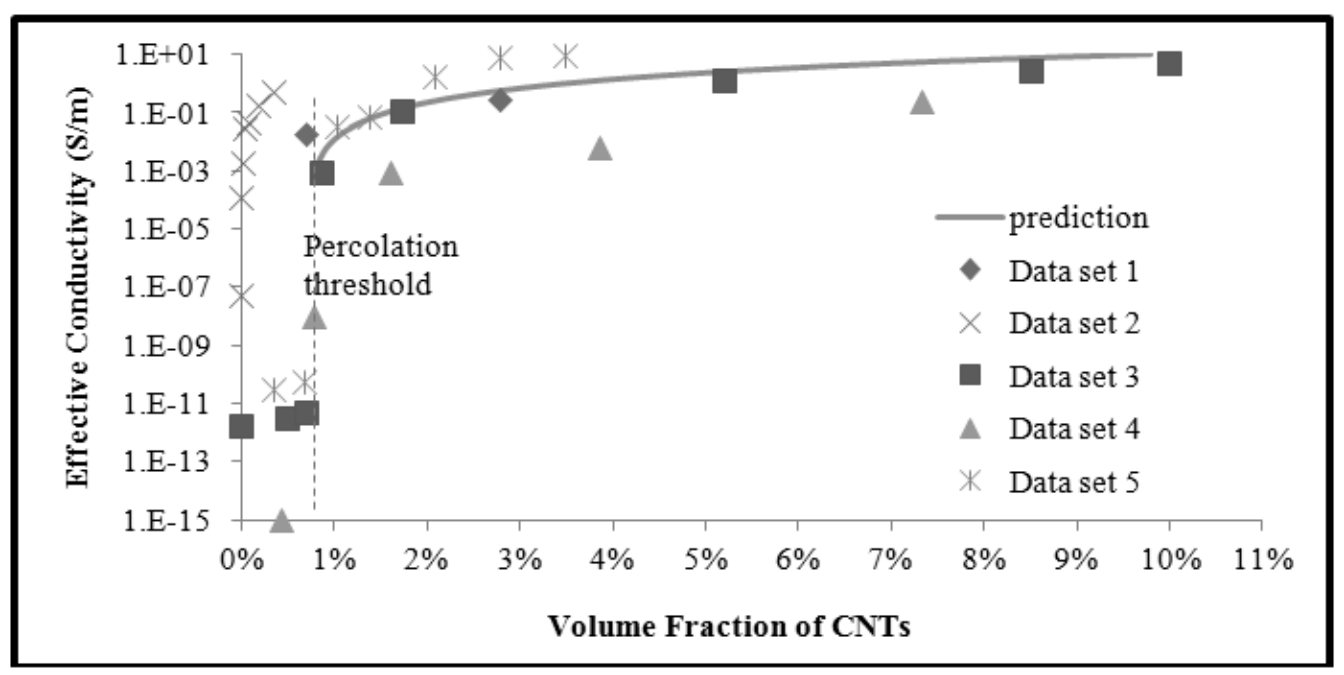

Figure 2 Data sets of MWNT composite conductivity and fitted prediction by power law

Note: Data set 1: random MWNT/epoxy [32]; Data set 2: aligned MWNT/epoxy [29]; Data set 3: MWNT/alumina[33]; Data set 4: MWNT/poly(ethylene terephthalate) [28]; Data set 5: MWNT/polycarbonate [34].

The Deng and Zhang model (see Appendix A) includes a polarization function $H(p)$, intrinsically determined by $p$. Therefore, the critical volume fraction is also a function of $p$, as shown by the curve "Prediction 1" in Figure 3. If the aspect ratio of the MWNTs is about 50, the percolation threshold is predicted to be $0.94 \mathrm{vol} \%$, which is slightly higher than the value identified by the experimental data sets (see Figure 2). Another simpler prediction of the percolation threshold is given in [35], where a simple exponential relationship between the critical volume fraction and the CNT aspect ratio as been assumed, namely $f_{c}=p^{-1.1 \pm 0.03}$ (see "Prediction 2" in Figure 3). However, for MWNTs with aspect ratio of 50, 
this percolation threshold model yields a critical volume fraction of $1.35 \%$, which is even higher than that predicted using the first method and almost double the experimental value.

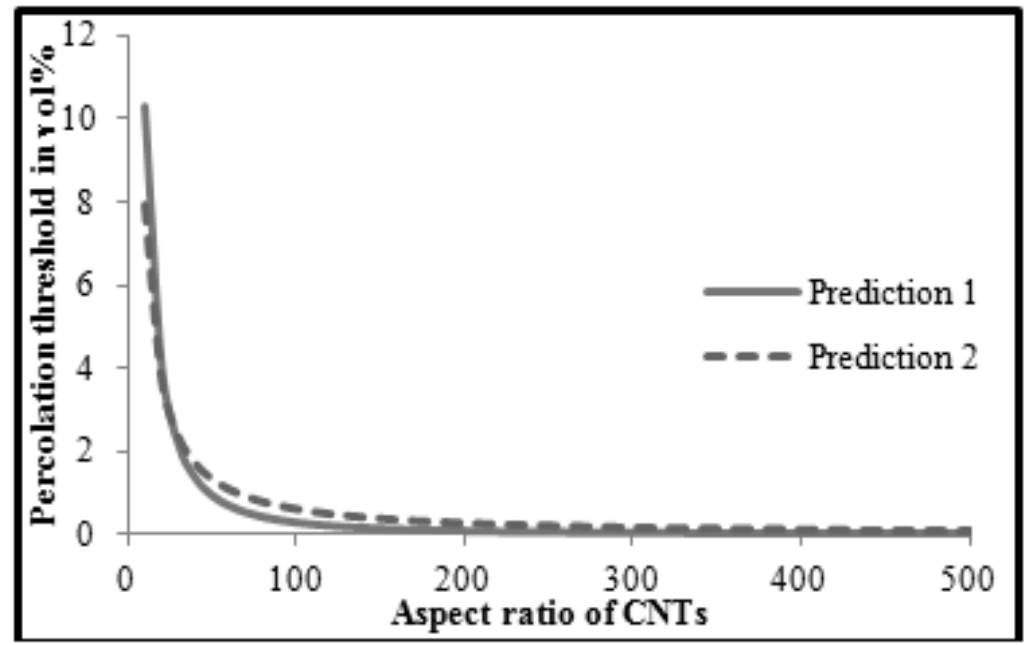

Figure 3 Percolation prediction for nanocomposites versus the CNT aspect ratio

At volume fractions below the threshold $f_{c}$, the matrix dominates the conductivity of the composite, due to the low contact density among nanoparticles. For randomly oriented MWNTs, the effective electrical conductivity of the composite $\left(\sigma_{e}\right)$ is given by [30]:

$$
\sigma_{e}=\sigma_{m}+\frac{\eta f / 3}{\frac{1}{\eta \sigma_{1}}+\frac{H}{\sigma_{m}}}
$$

For randomly oriented CNTs, the transverse conductivity can be neglected because it is two to three orders of magnitude lower than the axial one [36]. The waviness $\eta$ of the CNTs is calculated by taking the ratio between the straight-line distance between two ends and the length of the nanotube itself. An average value of 0.8 is taken for $\eta$ in this study [30]. Theoretically, the percentage $\xi$ of the percolated MWNTs depends on the CNT length and aspect ratio. However, it can be assumed that $\xi$ is proportional to $\sqrt[3]{f}$ (average measure of the nanoparticle separation [30]):

$$
\xi=\frac{\sqrt[3]{f}-\sqrt[3]{f_{c}}}{1-\sqrt[3]{f_{c}}}\left(f_{c} \leq f<1\right)
$$

For volume fractions above the percolation limit, the effective electrical conductivity of the composite is provided by both the un-percolated and percolated nanotubes (second and third terms of Eq. (3), respectively [30]):

$$
\sigma_{e}=\sigma_{m}+\frac{\left(1-\xi_{p}\right) \eta f}{3\left(\eta \sigma_{1}+\frac{H(\eta p)}{\sigma_{m}}\right)}+\frac{1}{3} \xi_{p} \hat{\eta}^{2} f \sigma_{1}
$$

Eqs. (A1-A3) and (1-3) describe the entire analytical approach to predict the effective conductivity of randomly oriented CNT/polymer composites for volume fractions of reinforcement up to $10 \%$ [30]. Figure 4 shows the predicted results compared with the experimental ones from $[27,33,37,38]$. It demonstrates that the model is in reasonable agreement with experiments carried out on PPESWNTs/polycarbonate and SWNTs/polyimide CP2 composites. At low CNT concentrations the 
conductivity of the composite is that of the matrix, i.e. usually below $10^{-12} \mathrm{~S} / \mathrm{m}$. Significant increases of the conductivity close to the percolation limits can be observed, followed by an asymptotic approach towards a constant dielectric behaviour. The effective conductivity tends to plateau above a 5\% volume fraction. This can be explained by the saturation of the conductive network within the matrix. For MWNTs/alumina, the model provides a good comparison with experimental data at high CNT concentrations, but fails to predict the percolation behaviour of MWNTs/alumina and SWNTs/PMMA at low CNT dispersions. A likely reason for this discrepancy is the uncertainty associated to the effective aspect ratio of the nanotubes. In the reminder of this work, the electrical properties of the composite will be estimated by Eqs. (A2-A3) and (1-3). The percolation threshold is set at $0.7 \mathrm{vol} \%$, i.e. the value suggested by both experimental data and the power law model.

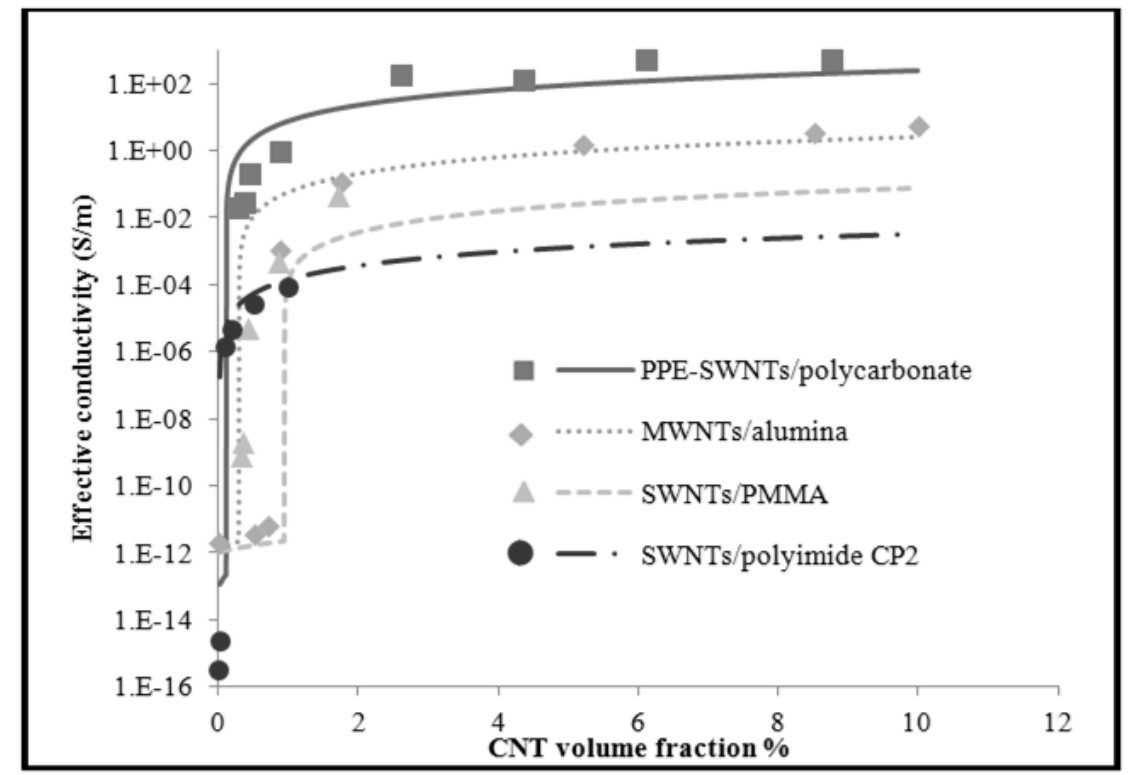

Figure 4 Data sets of CNT composite conductivities and fitted prediction by analytical model [30]

\section{Mechanical stiffness and strength of the equivalent matrix material}

The following assumptions are made for the analytical model that describes the mechanical properties of the equivalent matrix:

a) There is perfect bonding between the matrix and the nano inclusions;

b) The matrix is isotropic in nature and perfectly cured, with no void being present;

c) The matrix and the carbon nanotubes share the same experience the same strain level;

d) The carbon nanotubes are uniformly dispersed within the matrix, resulting in an isotropic nanocomposite.

Several homogenization models are available in open literature to predict the effective mechanical properties of nanocomposites with randomly distributed nanofillers (see Appendix B for the associated analytical expressions). The simplest one is the Voigt-Reuss model (basic rule of mixtures), which gives the upper and lower modulus boundaries with nanotubes being all aligned either along the load direction $\left(E_{L}\right)$, or orthogonally to the load (transverse direction) $\left(E_{T}\right)$ [39]. Hashin-Shritkman bounds assume that the nanocomposite is isotropic and quasi-homogeneous, and allow calculating limits for the shear modulus and bulk modulus of the nanocomposite [39]. The shear lag model combines the rule of mixtures with the Cox's model to predict the interfacial shear strength and the progressive debonding of the CNTs 
from the surrounding matrix under tensile loading. The shear lag models accounts for the geometry of the nanoparticles [40] and it leads to isotropic properties for the nanocomposite material. The Hui-Shia model takes into account the aspect ratio of the CNTs, and it has been successfully extended to predict the overall modulus of composites with fibre-like fillers [39]. The trends of Young's modulus versus the volume fraction of the nanofiller predicted by the analytical models listed above is shown in Figure 5 and compared to experimental data [41-44]. The test data tend to be close to the lower bounds because of the very significant large between the stiffness of the CNTs and that of epoxy matrix. It is worth of notice that the experimental data are related to different sets of polymer matrices. The test data \#1 show a tensile modulus that decreases beyond 1.5wt.\% CNT, because of the aggregation of the nanofillers [45]. However, it can be observed that the lower bound of the Hui-Shia model fits the two sets of the experimental data with sufficient accuracy. Therefore, the Hui-Shia model will be employed in the rest of the paper for the evaluation of the tensile modulus of the effective nanocomposite matrix.

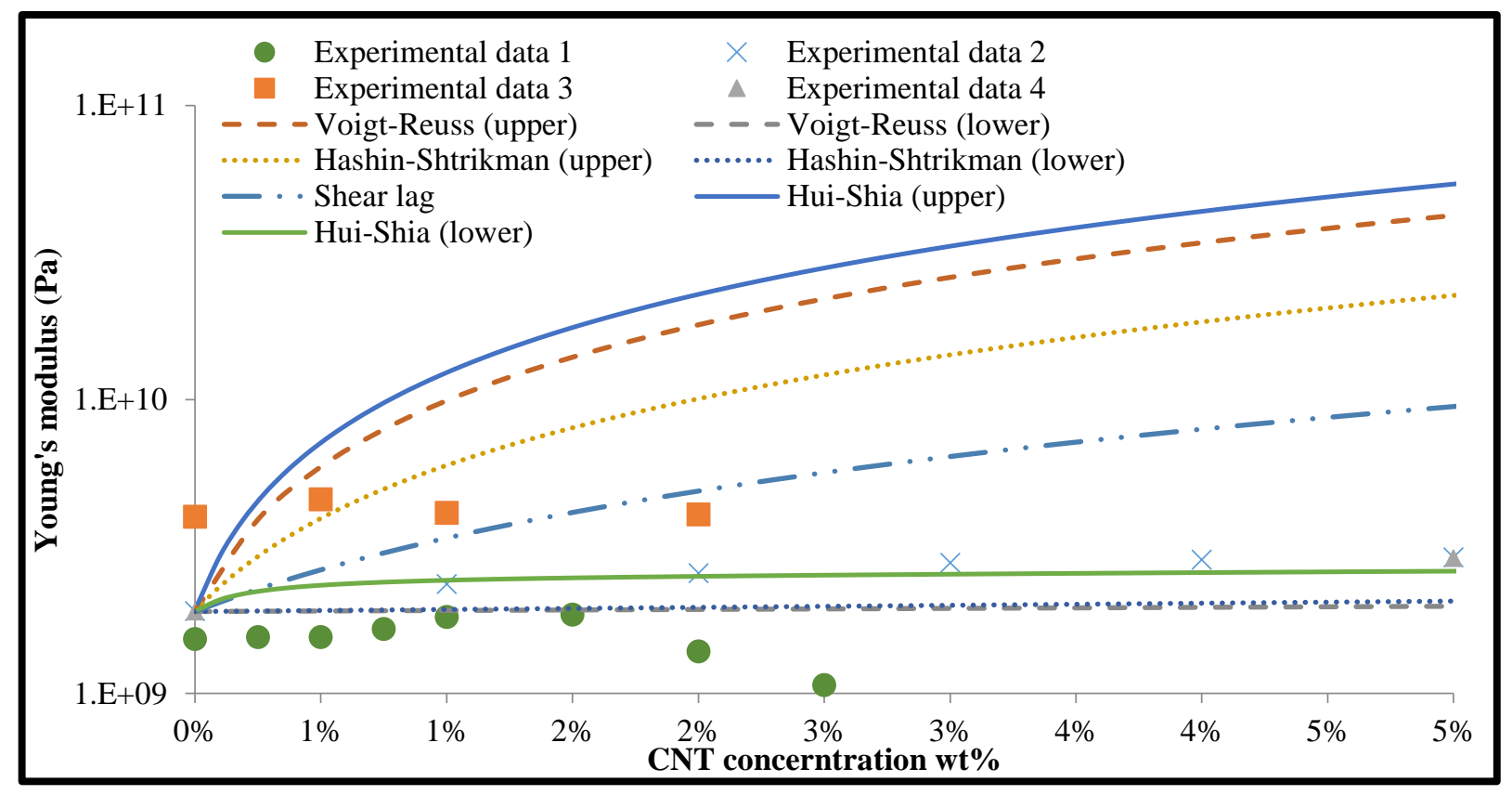

Figure 5 CNT reinforced stiffness of epoxy matrix (experimental and predicted data)

The Poisson's ratio is of the MWCNTs nanocomposites is assumed to be equal to 0.38 for simplicity [46]. The shear modulus is also considered by assuming the nanocomposite as an equivalent isotropic medium $\left(G_{12}=E / 2 / 1+v_{12}\right)$. The strength of the CNT composite is predicted by using the rule of mixtures, with a coefficient $\delta$ accounting the random distribution and orientation of nanotubes:

$$
X=\delta f_{n} X_{n}+\left(1-f_{n}\right) X_{m}
$$

Here the value of $\delta=0.2$ is used as recommended in [47].

\section{Dielectric and mechanical unidirectional ply models}

As carbon fibre are added into the effective matrix, the resulting conductivity is affected by a further percolation effect due to the presence of continuous fibre reinforcement. Below a critical CF volume fraction, the conductivity is still dominated by the effective matrix. However, above this critical value, the overall conductivity increases dramatically. The presence of the CNT reinforcement would reduce the percolation threshold of the carbon fibres in the polymer matrix due to the synergy existing between the $\mathrm{CF}$ and the CNT networks [48]. The percolation threshold of carbon fibers in polymer matrix is reported 
to be around $2.7 \mathrm{vol} \% \sim 4.3 \mathrm{vol} \%$ [48]. In aerospace applications, the fibre content in CFRP is usually around $40 \% \sim 70 \%$ in volume to ensure adequate strength and stiffness. This fibre content is much higher than the percolation threshold, therefore the in-plane current conduction would be dominated by the carbon fibres, which can be safely assumed to have percolated.

In terms of current conduction, the electrons may travel either along the fibres or through the conductive matrix. Thus the overall resistance of the composite can be obtained from the expression:

$$
\frac{1}{R_{C}}=\frac{1}{R_{f 1}}+\frac{1}{R_{f 2}}+\cdots+\frac{1}{R_{f n}}+\frac{1}{R_{m}}
$$

When considering the relation $R=\frac{l}{A} / \sigma$ in Eq. (5), we obtain after some manipulation:

$$
\begin{aligned}
& \sigma_{C}=\sigma_{f} \frac{\sum A_{f i}}{A_{C}}+\sigma_{m} \frac{A_{m}}{A_{C}} \\
& =\sigma_{f} f_{C F}+\sigma_{m}\left(1-f_{C F}\right)
\end{aligned}
$$

Eq (6) represents a rule of mixtures. The relation is valid for a composite with a sufficiently highconductivity matrix due to the dispersed CNTs. In the case of an insulating matrix, in which $\sigma_{m} \approx 0$, Eqn(6) reduces to:

$$
\sigma_{C} \approx f_{C F} \sigma_{f}
$$

The rule of mixtures is valid when all the fibres are aligned and the dielectric connectivity between fibers along the longitudinal direction is perfect. In an ideal case, all fibres are fully separated by the matrix along the transverse and through-thickness directions. In a non-conductive matrix, the transverse conductivity of the unidirectional lamina ought to be zero, assuming that no contact between parallel fibres exists. In reality random contacts between the fibers are always presents, due to the irregular arrangement of the reinforcement. Tse et al. [49] have developed an analytical model for the transverse conductivity of the unidirectional laminate based on the evaluation of the contact probability. The results from both the analytical model and experiments indicate that the transverse conductivity is in the range of $10 \sim 10^{2} \mathrm{~S} / \mathrm{m}$, which is roughly three orders of magnitude less than the longitudinal conductivity $\left(10^{4} \sim 10^{5} \mathrm{~S} / \mathrm{m}\right)$ [49]. For composites with cross-ply laminates or quasi-isotropic stacking sequence, the conduction of the current is dominated by plies with fibres aligned along the direction of the electric field. In the present work, the transverse and through-thickness conductivities of the CF/epoxy laminate are assumed to be $1 / 1000$ of the longitudinal one for simplicity. For CF/CNT/epoxy composite the transverse (or through-thickness) conductivity is calculated by placing in parallel the transverse (or throughthickness) conductivity of the CF composite with that of the effective matrix.

The stiffness of the UD ply is calculate using rule of mixture and Halpin-Tsai equations for the longitudinal $\left(E_{1}\right)$ and transverse $\left(E_{2}\right)$ Young's moduli [47]. A modified rule of mixtures [50] has been used to estimate the ultimate strength of unidirectional CF lamina along the fibres direction. This modification considers the misalignment and irregular distribution of fibres. The ultimate strength of the composite is given by [50]:

$$
\sigma_{c x}=\hat{\sigma}_{m}\left(1-f_{C F}\right)+\sigma_{C F} f_{C F}^{\prime}
$$

In (8) $P$ is related to the microstructure geometry of composite components and follows the empirical relationship with firesr volume fraction as proposed in [50]: 


$$
\begin{gathered}
P=0.4333-0.4888 f_{C F}, \quad \text { for } f_{C F}<0.54 \\
P=-0.2629+0.8006 f_{C F}, \quad \text { for } f_{C F} \geq 0.54
\end{gathered}
$$

The comparison between (8) and experimental data shows good agreement for fibres volume fraction from $\sim 30 \%$ to $\sim 70 \%$ [50]. The transverse strength can be estimated by considering the fibres as cylindrical holes in the matrix that reduce the load-bearing cross-section [47]:

$$
\sigma_{c y}=\hat{\sigma}_{m}\left[1-2\left(\frac{f_{C F}}{\pi}\right)^{1 / 2}\right]
$$

The shear strength is simply considered equal to the one of the matrix.

\section{Dielectric and mechanical laminate models}

The homogenized dielectric properties of the composite laminate are calculated with the approach suggested by Chin and Lee [51]. Details of the model are described in Appendix D.

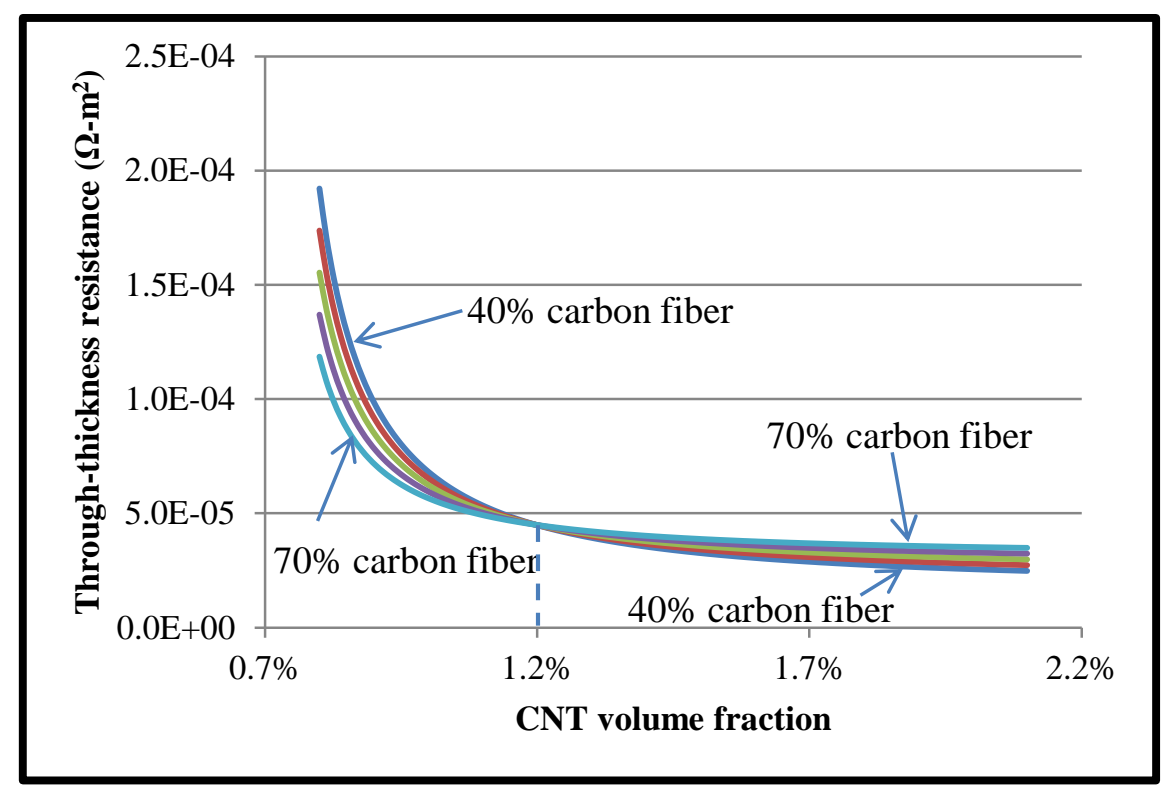

Figure 6 Through-thickness resistance trend with CNT and CF contents

One interesting phenomenon has been observed by applying Chin and Lee's model. As it can be observed in Figure 6, with CNTs below 1.2vol\% in the matrix, the through-the-thickness resistance of the laminate will decrease with the increase of carbon fibre content. This is because the transverse contact density is increased by higher carbon-fibre volume fractions. At a CNT concentration larger than $1.2 \mathrm{vol} \%$, the through-thickness resistance will decrease when more carbon fibers are placed into the laminate. This fact can be explained by considering that, for a CNT concentration above the $1.2 \mathrm{vol} \%$ threshold, the conductivity of the effective matrix exceeds that of the carbon fibre along the transverse direction. Therefore, the increase of carbon fibre content effectively affects the less conductive element in the composite, resulting in a decrease of the overall conductivity along the through-thickness direction.

Classical lamination theory [52] is applied here to estimate the stiffness of the laminate composites. Two typical stacking sequences have been investigated including cross-ply $[0 / 90]_{2 s}$ and quasi-isotropic (0/45/- 
45/90)s. Cross-ply laminate gives higher tensile modulus, while quasi-isotropic laminates have the higher shear stiffness (Table 5 and Table 6). In aerospace structures, the fuselage skin would be under longitudinal and hoop stresses. In rolling manoeuvre the fuselage would be also subject to torsional load which have to be supported by the $\pm 45^{\circ}$ plies [53]. Therefore, a quasi-isotropic stacking sequence is adopted here.

Table 5 Elastic variation with CNT content

\begin{tabular}{c|cccc}
\hline & \multicolumn{3}{|c}{ Tensile modulus $E_{x}$} & \multicolumn{2}{c}{ Shear modulus $G_{x y}$} \\
\hline CNTs vol.\% & cross-ply & quasi-iso & cross-ply & quasi-iso \\
0 & 75.1 & 49.4 & 3.92 & 18.1 \\
0.10 & 75.6 & 53.4 & 4.06 & 20.2 \\
0.50 & 76.3 & 54.2 & 4.51 & 20.5 \\
1 & 76.6 & 54.6 & 4.72 & 20.6 \\
2 & 76.9 & 54.9 & 4.91 & 20.8 \\
5 & 77.4 & 55.4 & 5.16 & 21 \\
\hline
\end{tabular}

Note: $\mathrm{CF}$ volume fraction fixed at $50 \%$; ply thickness fixed at $0.125 \mathrm{~mm}$.

Table 6 Elastic variation with $\mathbf{C F}$ content

\begin{tabular}{c|cccc}
\hline & \multicolumn{2}{|c}{ Tensile modulus $E_{x}$} & \multicolumn{2}{c}{ Shear modulus $G_{x y}$} \\
\hline cf vol\% & $\begin{array}{c}\text { cross- } \\
\text { ply }\end{array}$ & $\begin{array}{c}\text { quasi- } \\
\text { iso }\end{array}$ & cross-ply & $\begin{array}{c}\text { quasi- } \\
\text { iso }\end{array}$ \\
40 & 61.9 & 44.1 & 3.86 & 16.7 \\
50 & 76.9 & 54.9 & 4.91 & 20.8 \\
60 & 92.6 & 66.5 & 6.44 & 25.2 \\
70 & 109 & 79.5 & 8.85 & 30.1 \\
\hline
\end{tabular}

Note: CNT volume fraction fixed at $2 \%$; ply thickness fixed at $0.125 \mathrm{~mm}$. 


\section{Optimization process for the multifunctional design of the composite}

The longitudinal electrical resistance of a fuselage can be approximated as:

$$
\begin{gathered}
R_{x}=\rho_{x} \frac{L}{A}=\frac{1}{\sigma_{x}} \frac{L}{C t_{s}} \\
\Rightarrow R_{x} \sim \frac{1}{\sigma_{x} t_{s}} \text { with fixed } L \text { and } C
\end{gathered}
$$

Similarly, the circumferential resistance can be approximated as:

$$
R_{y} \sim \frac{1}{\sigma_{y} t_{s}}
$$

Along the through-thickness direction, if one assumes that the area of the lighting strike attachment is $A_{L}$, it is possible to write:

$$
\begin{gathered}
R_{z}=\frac{1}{\sigma_{y}} \frac{t_{s}}{A_{L}} \\
\Rightarrow R_{z} \sim \frac{t_{s}}{\sigma_{z}}
\end{gathered}
$$

The weight of the structure (or mass of per unit surface) is also one of the objectives to be minimized:

$$
\hat{\rho}=\rho_{c} t_{s}
$$

The composite density is obtained by the simple rule of mixture as:

$$
\rho_{c}=\left[\rho_{n} f_{n}+\rho_{m}\left(1-f_{n}\right)\right]\left(1-f_{C F}\right)+\rho_{C F} f_{C F}
$$

The variables to be optimized include the contents of CNT and CF in the matrix, the number of plies and the ply thickness. The lower boundary for the CNT fraction is set to be $0.7 \%$ for the formation of conducting networks. The upper boundary of CNT fraction is set to be $2 \%$ to prevent clustering effects that degrade the conductivity and the mechanical properties. To simplify the model calculations the CNT fraction here is defined as the fraction to epoxy matrix, instead of to the whole composite. Classical volume fractions of the carbon fibres in CFRPs are between 40\% 70\%. The lower volume fraction could not provide enough stiffness and strength for the composite, and has problem with the formation of conducting network if it is less than $6.3 \%$. CF volume fractions higher than $70 \%$ have problems of carbon saturation within the epoxy matrix. To facilitate to possible manufacturing, all the plies in the composite are assumed to have a uniform thickness $t_{p}$. In this study, the ply thickness can vary between $0.1 \mathrm{~mm}$ and $0.2 \mathrm{~mm}$. To maintain the symmetric quasi-isotropic layout the laminate stacking repeats the $(0 / \pm 45 / 90)_{\mathrm{s}}$ sequence, therefore the number of plies has to have values multiple of $8(8,16,24$, and 32). In the cost function of the optimisation this is represented by a parameter $n$ varying between 0.51 and 4.49 , while the number of plies is obtained as $8 \times \operatorname{round}(n)$. All the variables are summarized in Table 7 .

Table 7 Optimized variables

\begin{tabular}{cccc}
\hline Variable name & Notation & Lower boundary & Upper boundary \\
\hline Volume fraction of & $f_{n}$ & $0.7 \%$ & $2 \%$ \\
CNT* $^{*}$ & & & \\
Volume fraction of CF & $f_{C F}$ & $40 \%$ & $70 \%$ \\
Number of plies & $N$ & 8 & 32 \\
\hline
\end{tabular}




*volume fraction of CNT in respect to the effective matrix

Hoop and longitudinal stresses are considered as the load cases to calculate the strength:

$$
\begin{gathered}
\sigma_{\text {Hoop }}=\frac{p r}{N t_{p}} \\
\sigma_{\text {Longitudinal }}=\frac{p r}{2 N t_{p}}
\end{gathered}
$$

The fuselage is viewed as a pressure vessel with a diameter of 5.96m [54]. The pressure difference between the inside and outside is 0.276 bar as recommended in reference [53]. The dimensions of the fuselage panel are given in [55] as $27.94 \mathrm{~cm} \times 41.66 \mathrm{~cm}$ for wide body transport aircraft. The failure criterion used here is the Tsai-Hill one [52], which considers stress interactions along both the global $\mathrm{x}$ and y directions of the laminate. The ply failure index is given by:

$$
\text { F.I. }=\left(f_{1} / X\right)^{2}+\left(f_{2} / Y\right)^{2}+\left(f_{12} / S\right)^{2}-\left(f_{1} / X\right)\left(f_{2} / X\right)
$$

The $X(Y)$ function is taken as follows:

$$
\begin{aligned}
& X(Y)=X_{t}\left(Y_{t}\right) \text { when } f_{1}\left(f_{2}\right) \geq 0 ; \\
& X(Y)=X_{c}\left(Y_{c}\right) \text { when } f_{1}\left(f_{2}\right)<0 .
\end{aligned}
$$

Ply failure occurs when the failure index exceeds 1, i.e. F.I. $<1$ must be satisfied for no ply failure. The Fitness function for the optimization with constraints is therefore developed as follows:

$$
\begin{aligned}
& \text { Fitness }=\text { Objective }, \quad \text { when } \max (F . I .)<1 \\
& \text { Fitness }=\text { Infinity }, \quad \text { when } \max (F . I .) \geq 1
\end{aligned}
$$

This is a multi-objective optimization process with three cost functions to be minimized regarding three variables. The genetic algorithm (GA) has been used to search the best solution for least resistance and areal weight [56] (Matlab Optimization Toolbox). To avoid having the GA population confined around the local optimal point, random perturbations have been applied by the mutation operation. Two criterions to terminate GA process have been applied: the upper limit of the generation number and minimum

\begin{tabular}{|c|c|c|c|}
\hline Objective index & Obj_1 & Obj_2 & Obj_3 \\
\hline Objective meaning & $\begin{array}{l}\text { In-plane } \\
\text { resistance }\end{array}$ & $\begin{array}{l}\text { Through-thickness } \\
\text { resistance }\end{array}$ & $\begin{array}{c}\text { Surface } \\
\text { mass }\end{array}$ \\
\hline $\begin{array}{l}\text { Objective } \\
\text { expression }\end{array}$ & $1 / \sigma_{x} N t_{p}$ & $N t_{p} / \sigma_{z}$ & $\hat{\rho}$ \\
\hline Design space & $0.0089 \sim 0.075 \Omega$ & $\begin{array}{c}2.3 \sim 6.5 \times 10^{-5} \Omega- \\
\mathrm{m}^{2}\end{array}$ & $4 \sim 8 \mathrm{~kg} / \mathrm{m}^{2}$ \\
\hline
\end{tabular}
change in average of solutions. All the parameters in the GA analysis have been taken as the default values from the Matlab GA tool, except for the size of the population. Several sizes of population have been tested, and after observing the Pareto optimal front the size of 400 for the population has been used to provide both good frontal line and reasonable computing time. The design spaces for all the three objectives extracted from the initial Pareto curves are shown in Table 8.

Table 8 Objectives and weights summary 


\begin{tabular}{l|lll}
\hline Weight parameter & $\alpha$ & $\beta$ & $\gamma$ \\
\hline
\end{tabular}

The objectives have been non-dimensionalised between 0 and 1 using the following formula:

$$
O b j^{*}=\frac{O b j-S_{L}}{S_{H}-S_{L}}
$$

The non-dimensional objectives a 3D Pareto surface have been generated (Figure 7) and fitted with polynomial functions as follows:

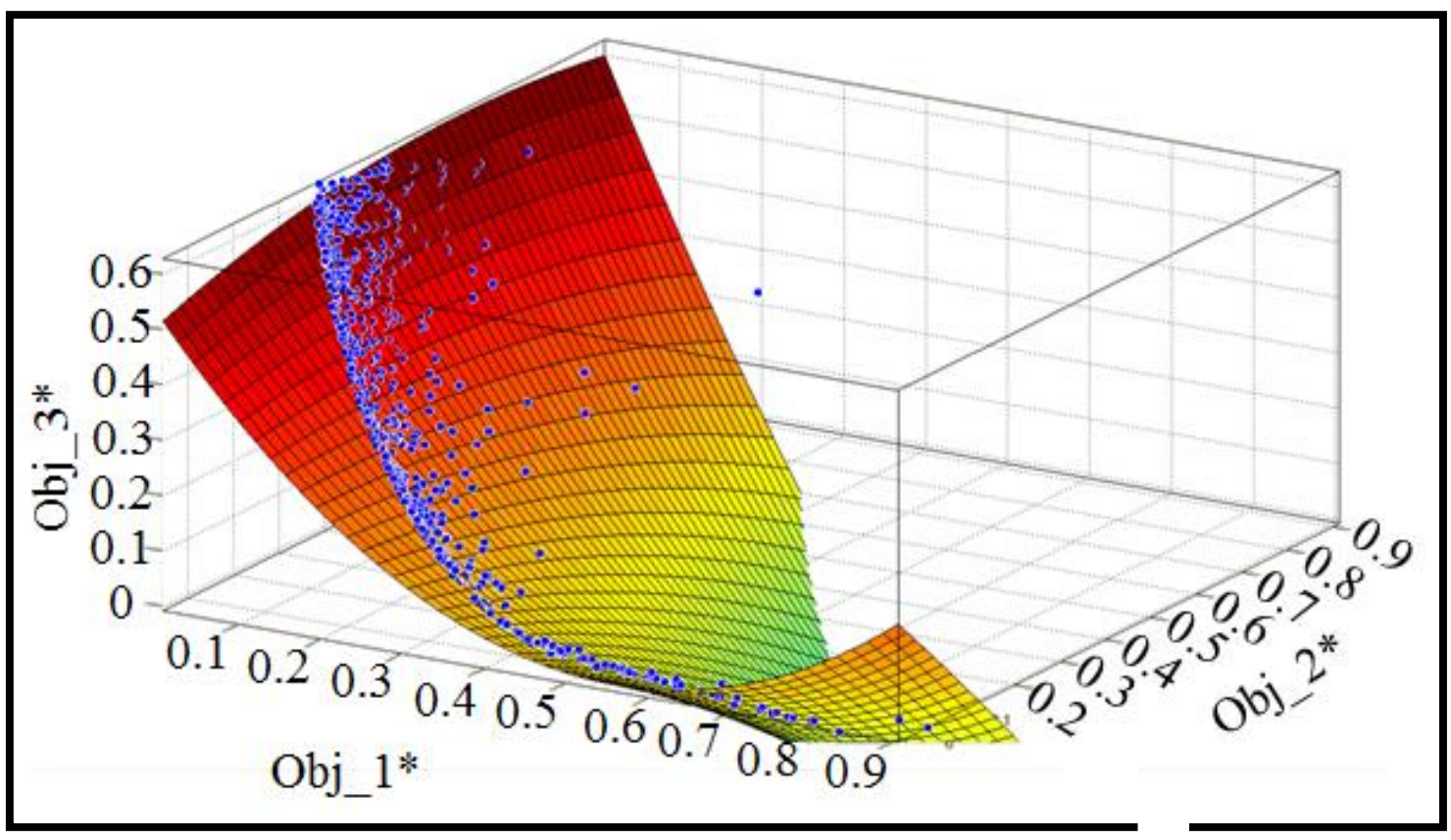

Figure 7 3-D Pareto surface

$$
z=f(x, y)=p_{00}+p_{10} x+p_{01} y+p_{20} x^{2}+p_{11} x y+p_{02} y^{2}
$$

In (24), $x, y$ and $z$ represent $O b j \_1 *, O b j \_2 *$ and Obj_3* respectively. The coefficients of Eq. (24) with $95 \%$ of confidence bounds are $p_{00}=0.5469(0.5439,0.55), p_{10}=-1.968 \quad(-1.98,-1.956), p_{01}=0.3051$ $(0.2918,0.3183), p_{20}=1.681(1.669,1.693), p_{11}=-1.629(-1.656,-1.603)$ and $p_{02}=-0.2401 \quad(-0.255$, 0.2253). To obtain the nominal best solution, all the three non-dimensional objectives are summed up with weights denoted as $\alpha, \beta$, and $\gamma$ that represent the importance for each of the objectives to construct the fitness of the design:

$$
\text { Fitness }=\sqrt{\alpha \times O b j \_1^{* 2}+\beta \times O b j \_2^{* 2}+\gamma \times O b j \_3^{* 2}}
$$

The variation of the weights enables to shift the emphasis of the three objectives. The fitness has been optimized for different combinations of weights, and the results can be observed in Table 9. Test \#7 emphasizes in-plane resistance, while test \#3 highlights the importance of the through-thickness resistivity and test 1 weights more the surface mass. The rest tests have more balanced ratios between 
objectives. Test \#4 gives the solution considering all objectives equally. From test 1 to test 7 the weight for the in-plane resistivity increases from 0.2 to 0.6 ; correspondingly, the optimal results of the in-plane resistivity decrease from $15.59 \mathrm{~m} \Omega$ to $12.61 \mathrm{~m} \Omega$. Similarly, the through-thickness resistivity varies from $32.20 \Omega-\mathrm{mm}^{2}$ in test 3 with a weight of 0.6 to $37.81 \Omega-\mathrm{mm}^{2}$ in test \#7 with a weight of 0.2 . The surface mass varies from $4.57 \mathrm{~kg} / \mathrm{m}^{2}$ in test 1 with a weight of 0.6 , to $5.65 \mathrm{~kg} / \mathrm{m}^{2}$ in test 7 with a weight of 0.2 .

Table 9 Results for difference weight combinations

\begin{tabular}{|c|c|c|c|c|c|c|c|c|c|c|}
\hline Test & $\alpha$ & $\beta$ & $\gamma$ & CNT\% & CF\% & $\begin{array}{c}\text { Num. of } \\
\text { plies }\end{array}$ & $\begin{array}{c}\text { Ply } \\
\text { thickness } \\
\text { mm }\end{array}$ & $\begin{array}{c}\text { In-plane } \\
\text { resistivity } \\
\mathrm{m} \Omega\end{array}$ & $\begin{array}{c}\text { Through- } \\
\text { thickness } \\
\text { resistivity } \\
\Omega_{-}-\mathbf{m m}^{2}\end{array}$ & $\begin{array}{c}\text { Surface } \\
\text { mass } \\
\mathbf{k g} / \mathrm{m}^{2}\end{array}$ \\
\hline 1 & \multirow{3}{*}{0.2} & 0.2 & 0.6 & 0.02 & 0.7 & 16 & 0.171 & 15.59 & 34.25 & 4.57 \\
\hline 2 & & 0.4 & 0.4 & 0.02 & 0.7 & 16 & 0.175 & 15.22 & 32.98 & 4.68 \\
\hline 3 & & 0.6 & 0.2 & 0.02 & 0.7 & 16 & 0.182 & 14.65 & 32.20 & 4.86 \\
\hline 4 & 0.33 & 0.33 & 0.33 & 0.02 & 0.7 & 16 & 0.188 & 14.23 & 33.27 & 4.60 \\
\hline 5 & \multirow{2}{*}{0.4} & 0.2 & 0.4 & 0.02 & 0.7 & 16 & 0.182 & 14.10 & 35.60 & 5.05 \\
\hline 6 & & 0.4 & 0.2 & 0.02 & 0.7 & 24 & 0.133 & 13.42 & 34.39 & 5.30 \\
\hline 7 & 0.6 & 0.2 & 0.2 & 0.02 & 0.7 & 24 & 0.141 & 12.61 & 37.81 & 5.65 \\
\hline
\end{tabular}

All the optimal solutions appear to approach the upper boundaries of the variable, i.e. $2 \%$ for CNT volume fraction and $70 \%$ for carbon fiber volume fraction. This fact can be further confirmed by plotting these results in the Pareto curves in Figure 8. All of the optimal solutions (denoted as red points) are along the edge of the design boundary, meaning that the optimization is limited by the variable boundaries. A further improvement of the objectives is dependent upon the expansion of the variable boundary. The results for ply thickness vary from $0.171 \mathrm{~mm}$ to $0.188 \mathrm{~mm}$ for a 16 -ply stack $\left([0 / \pm 45 / 90]_{2 \mathrm{~s}}\right)$, and from $0.133 \mathrm{~mm}$ to $0.141 \mathrm{~mm}$ for a 24 -ply stacking sequence $\left([0 / \pm 45 / 90]_{3 \mathrm{~s}}\right)$. With greater panel thickness, the in-plane conducting path becomes larger and increases the mobility of the electrons. The length of the through-thickness conducting path would be also increased, resulting therefore in higher resistivity. The test \#4, which represents equal weights for all objectives, has been considered to evaluate the effect of adding MWNTs into the CFRP (Table 10). It can be observed that the improvement of the inplane conductivity is quite limited because of the high conductivity of carbon fibre itself. The majority of the improvement in the conductivity is observed along the through-thickness direction (up by $82.19 \%$ ). The stiffness properties have been improved in a limited way, by $13.73 \%$ for the Young's modulus and $18.78 \%$ for the shear modulus. As a result, the maximum failure index under the specific load case is reduced by $19.05 \%$, which implies that the failure margin has been extended.

For the optimization scenario \#4, the average through-thickness longitudinal and hoop stresses on the fuselage panel are $27 \mathrm{MPa}$ and $54 \mathrm{MPa}$, respectively. These correspond to an average principal strain of $700 \mu \mathrm{m}$ at ultimate load, which is a value compatible with damage tolerant design requirements. 


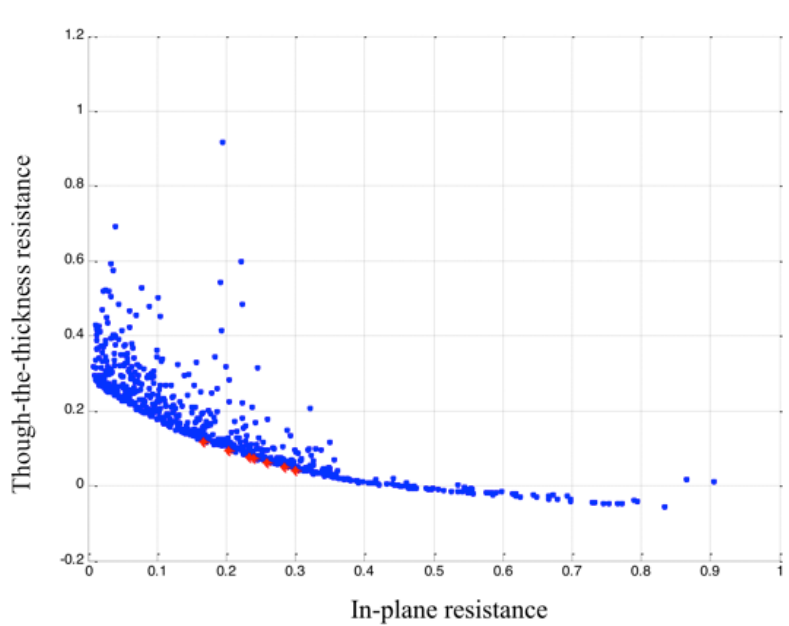

(a) $O b j \_1 *$ against $O b j \_2 *$

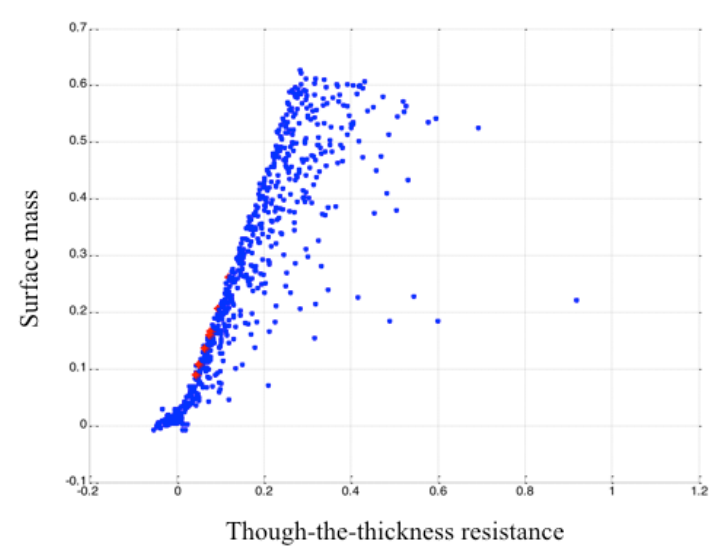

(b) $\mathrm{Obj}_{-} 1 *$ against $\mathrm{Obj} \_3 *$

Figure 8 Weighted solutions

Table 10 Improvement of CF/epoxy properties with CNT \% vol

\begin{tabular}{c|ccc}
\hline & CF/epoxy & CNT/CF/epoxy & Improvement \\
\hline CNT vol\%* & 0 & 2 & \\
CF vol\% & 70 & 70 & \\
Num. of plies & 16 & 16 & \\
Ply thickness (mm) & 0.188 & 0.188 & \\
Conductivity $\sigma_{x}(\mathrm{~S} / \mathrm{m})$ & 23345 & 23423 & $0.33 \%$ \\
Conductivity $\sigma_{z}(\mathrm{~S} / \mathrm{m})$ & 46.69 & 85.06 & $82.19 \%$ \\
Young's modulus $(\mathrm{GPa})$ & 69.98 & 79.59 & $13.73 \%$ \\
Shear modulus $(\mathrm{GPa})$ & 25.39 & 30.16 & $18.78 \%$ \\
maximum $\mathrm{F} . \mathrm{I}$. & 0.771 & 0.625 & $-19.05 \%$ \\
Areal weight $\left(\mathrm{kg} / \mathrm{m}^{2}\right)$ & 5.011 & 5.018 & $0.13 \%$ \\
\hline
\end{tabular}

*volume fraction of CNT is in respect of the effective matrix. 


\section{Conclusion}

In this study the CNT/CF/epoxy composite architecture has been modelled and optimized for a fuselage panel case against lightning strike. The study has theoretically proved that by adding CNTs into the effective epoxy matrix the electrical bulk conductivity and elastic stiffness of CFRP can be increased. The major increase in electrical conductivity can be observed along the through-thickness direction, and it reaches as high as $82.19 \%$ by adding $2 \%$ CNT into the effective matrix. Only marginal improvement $(0.33 \%)$ on the in-plane conductivity is obtained by dispersing CNTs, being this conductivity dominated by the carbon fibers. Moderate increases of $13.7 \%$ and $18.8 \%$ in tensile and shear modulus respectively have also been identified. These results imply that the CNT can improve the current conducting ability of CFRP without specific loss in mechanical properties when uniform dispersions are achieved. The model also provides practical suggestions on how to improve the conductive network in the hybrid nanocomposites in terms of percolation threshold, maximum efficiency for the through-the-thickness conductivity and allowable ply thickness configurations. Conductive paints for airframe applications can also be investigated using the same effective matrix approach developed in this study, which could help on designing coating strategies to further reduce the use of traditional methods for composite lightning protection of aircraft.

\section{References}

1. Uman, V.A.R.a.M.A., LIGHTNING Physics and Effects. 2003: Cambridge University Press.

2. Fofana, I., et al., Modelling a positive lightning downward leader to study its effects on engineering systems. Generation, Transmission and Distribution, IEE Proceedings-, 1998. 145(4): p. 395-402.

3. Aerospace recommended practice, in Aircraft lightning environment and related test waveforms. 1999, SAE.

4. Feraboli, P. and M. Miller, Damage resistance and tolerance of carbon/epoxy composite coupons subjected to simulated lightning strike. Composites Part A: Applied Science and Manufacturing, 2009. 40(6-7): p. 954-967.

5. Peng, H.-X., Polyurethane Nanocomposite Coatings for Aeronautical Applications, in Multifunctional Polymer Nanocomposites. Taylor \& Francis Group.

6. Niu, M.C.Y., Composite Airframe Structures, Practical Design Information and Data. 1996: HONG KONG CONMILIT PRESS LTD.

7. Ling, R., FATIGUE RESISTANCE OF LIGHTNING STRIKE PROTECTION. 2007, University of Bristol.

8. Rupesh Khare, S.B., Carbon Nanotube Based Composites - A Review. Journal of Minerals \& Materials Characterization \& Engineering, 2005. 4(1): p. 31-46.

9. Paipetis, A. and V. Kostopoulos, Carbon nanotube enhanced aerospace composite materials: a new generation of multifunctional hybrid structural composites. Vol. 188. 2012: Springer Science \& Business Media.

10. Trimble, S. Lockheed Martin reveals F-35 to feature nanocomposite structures. 2011 [cited 2015 13/07]; Available from: http://www.flightglobal.com/news/articles/lockheed-martin-reveals-f-35-to-feature-nanocomposite-357223.

11. Kruckenberg, T.M., et al., Low density lightning strike protection for use in airplanes. 2015, Google Patents.

12. Yuan, J., G. Allegri, and F. Scarpa, Buffeting mitigation using carbon nanotube composites: a feasibility study. Proceedings of the Institution of Mechanical Engineers, Part G: Journal of Aerospace Engineering, 2013. 227(9): p. $1425-1440$.

13. Davies, A.L. and P.T. Curtis. Fatigue in Aerospace Applications. In: Fatigue in Composites. Bryan Harris Ed., Woodhead Publishing, 2000.

14. Bak, B.L., et al., Delamination Under Fatigue Loads in Composite Laminates: A Review on the Observed Phenomenology and Computational Methods. Applied Mechanics Reviews, 2014. 66(6): p. 060803.

15. Dong, Q., et al., Coupled electrical-thermal-pyrolytic analysis of carbon fiber/epoxy composites subjected to lightning strike. Polymer, 2015. 56: p. 385-394.

16. Reid, G., Mechanical damage to aircraft structures from lightning strikes. Journal of Aerospace Engineering, 1993. 207: p. 1-14.

17. Aerospace recommended practice, in Aircraft Lightning Zoning. 2005, SAE.

18. Multi Walled Carbon Nanotubes (CheapTubes.com). [cited 2011 06/10]; Available from: http://www.cheaptubesinc.com/MWNTs.htm.

19. Al-Saleh, M.H. and U. Sundararaj, A review of vapor grown carbon nanofiber/polymer conductive composites. Carbon, 2009. 47(1): p. 2-22.

20. Hall, L.J., et al., Sign Change of Poisson's Ratio for Carbon Nanotube Sheets. Science, 2008. 320(5875): p. $504-507$. 
21. Yuan, J., et al., Novel parametric reduced order model for aeroengine blade dynamics. Mechanical Systems and Signal Processing, 2015. 62: p. 235-253.

22. TORAYCA, T300 DATA SHEET.

23. HexTow, IM7 Product Data.

24. Zheng, Q.S. and D.X. Du, An explicit and universally applicable estimate for the effective properties of multiphase composites which accounts for inclusion distribution. Journal of the Mechanics and Physics of Solids, 2001. 49(11): p. 2765-2788.

25. Balberg, I., et al., Excluded volume and its relation to the onset of percolation. Physical Review B, 1984. 30(7): p. 3933.

26. Kirkpatrick, S., Percolation and Conduction. Reviews of Modern Physics, 1973. 45(4): p. 574.

27. Du, F., J.E. Fischer, and K.I. Winey, Effect of nanotube alignment on percolation conductivity in carbon nanotube/polymer composites. Physical Review B, 2005. 72(12): p. 121404.

28. $\mathrm{Hu}, \mathrm{G}$., et al., Low percolation thresholds of electrical conductivity and rheology in poly(ethylene terephthalate) through the networks of multi-walled carbon nanotubes. Polymer, 2006. 47(1): p. 480-488.

29. Moisala, A., et al., Thermal and electrical conductivity of single-and multi-walled carbon nanotube-epoxy composites. Composites Science and Technology, 2006. 66(10): p. 1285-1288.

30. Deng, F. and Q.-S. Zheng, An analytical model of effective electrical conductivity of carbon nanotube composites. Applied Physics Letters, 2008. 92(7): p. 071902-071902-3.

31. Logakis, E., et al., Low electrical percolation threshold in poly(ethylene terephthalate)/multi-walled carbon nanotube nanocomposites. European Polymer Journal, 2010. 46(5): p. 928-936.

32. Allaoui, A., et al., Mechanical and electrical properties of a MWNT/epoxy composite. Composites Science and Technology, 2002. 62(15): p. 1993-1998.

33. Kaleem Ahmad, W.P., Sui-Lin Shi, Electrical conductivity and dielectric properties of multiwalled carbon nanotube and alumina composites. Applied Physics Letters, 2006. 89.

34. Pötschke, P., A.R. Bhattacharyya, and A. Janke, Melt mixing of polycarbonate with multiwalled carbon nanotubes: microscopic studies on the state of dispersion. European Polymer Journal, 2004. 40(1): p. 137-148.

35. Ning, H. and et al., The electrical properties of polymer nanocomposites with carbon nanotube fillers. Nanotechnology, 2008. 19(21): p. 215701.

36. Mitchell, E.W.J. and M.R. Taylor, Mechanism of Stored-Energy Release at 200[deg] C in Electron-Irradiated Graphite. Nature, 1965. 208(5011): p. 638-641.

37. Z. Ounaies, C.P., K.E. Wise, E.J. Siochi, J.S. Harrison, Electrical properties of single wall carbon nanotube reinforced polyimide composites. Composites Science and Technology, 2003. 63: p. 1637-1646.

38. Rajagopal Ramasubramaniam, J.C., Haiying Liu, Homogeneous carbon nanotubeÕpolymer composites for electrical applications. Applied Physics Letters, 2003. 83.

39. Hurang Hu, L.O., Ayo Abatan, Characterizing and Modeling Mechanical Properties of Nanocomposites-Review and Evaluation. Minerals \& Materials Characterization \& Engineering, 2010. 9(4): p. 275-319.

40. Muc, A. and M. Jamróz, Homogenization Models for Carbon Nanotubes. Mechanics of Composite Materials, 2004. 40(2): p. 101-106.

41. Yeh, M.K.H., T. H., Dynamic Properties of MWNTS/Epoxy Nanocomposite Beams. KEY ENGINEERING MATERIALS, 2007. 334/335: p. 709-712.

42. Yeh, M.-K., T.-H. Hsieh, and N.-H. Tai, Fabrication and mechanical properties of multi-walled carbon nanotubes/epoxy nanocomposites. Materials Science and Engineering: A, 2008. 483-484(0): p. 289-292.

43. Y. Liu, H.X.P., F. Scarpa, C. D. L. Remillat, Large frequency bandwidth damping in MWCNT nanocomposites, in ACCIS. University of Bristol: Bristol.

44. Xiao, K.Q., L.C. Zhang, and I. Zarudi, Mechanical and rheological properties of carbon nanotube-reinforced polyethylene composites. Composites Science and Technology, 2007. 67(2): p. 177-182.

45. Liang Shu-quan, J.C.-a., Tang Yan, Zhang Yong, Zhong Jie, Pan An-qiang, Mechanical and electrical properties of carbon nanotube reinforced epoxide resin composites. Transactions of Nonferrous Metals Society of China, 2007. 17: p. 675-679.

46. Y. Liu, H.X.P., F. Scarpa, C. D. L. Remillat, Large frequency bandwidth damping in MWCNT nanocomposites, in Advanced Composites Centre for Innovation and Science. University of Bristol: Bristol.

47. Clyne, D.H.a.T.W., An Introduction to Composite Materials. 1996: Cambridge University Press.

48. R. Taipalus, T.H., M.Q. Zhang, K. Friedrich, The electrical conductivity of carbon-fibre-reinforced polypropylene/polyaniline complex-blends: experimental characterisation and modelling. Composites Science and Technology, 2001. 61: p. 801-814.

49. Tse, K.W., C.A. Moyer, and S. Arajs, Electrical conductivity of graphite fiber-epoxy resin composites. Materials Science and Engineering, 1981. 49(1): p. 41-46.

50. Modified Rule of Mixtures for Prediction of Tensile Strength of Unidirectional Fiber-reinforced Composites. Journal of Materials Science Letters, 1998. 17(19): p. 1601-1603.

51. Chin, W. and D. Lee, Laminating rule for predicting the dielectric properties of E-glass/epoxy laminate composite. Composite Structures, 2007. 77(3): p. 373-382.

52. DATOO, M.H., MECHANICS OF FIBROUS COMPOSITES. 1991: ELSEVIER APPLIED SCIENCE.

53. Howe, D., Aircraft Loading and Structural Layout. 2004: American Institute of Aeronautics Inc. 
54. Mansfield, E. and A. Sobey, Fiber Composite Helicopter Blade. 1. Stiffness Properties. 2. Prospects for Aeroelastic Tailoring. Aeronautical Quarterly, 1979. 30(MAY): p. 413-449.

55. Lusk, J., Wing and Fuselage Structural Optimization Considering Alternative Material Systems. 2006, University of Kansas.

56. Almeida, F.S. and A.M. Awruch, Design optimization of composite laminated structures using genetic algorithms and finite element analysis. Composite Structures, 2009. 88(3): p. 443-454.

57. Karippal, J., et al., Electrical and Thermal Properties of Twin-Screw Extruded Multiwalled Carbon Nanotube/Epoxy Composites. Journal of Materials Engineering and Performance, 2010. 19(8): p. 1143-1149. 


\section{Appendix A - dielectric nanocomposite model}

The power law is the most commonly accepted prediction for the effective conductivity of nanocomposites [27-29]:

$$
\sigma_{c}=\sigma_{0}\left(f_{n}-f_{c}\right)^{t}, f>f_{c}
$$

The exponent $t$ depends on the orientation and distribution of the nanoparticles in the composite, usually 1 1.3 for 2D systems, 1.6 2 for 3D systems, and $t>2$ for some anisotropic systems [57]. The constant $\square$ o depends upon the geometry parameters of the CNTs (mainly the aspect ratio), and it is taken equal to the conductivity $\square_{I I}$ of the nanotubes for simplicity.

Another scheme for predicting effective conductivity of nanocomposites is the analytical model developed by Deng and Zhang [30]. In this model the prediction of the percolation threshold is based on the aspect ratio of nanotubes. For volume fractions below and above the percolation threshold, different sets of formulae are derived to evaluate the electrical conductivity. The percolation is estimated by [30]:

Where:

$$
f_{c}=\frac{9 H(1-H)}{-9 H^{2}+15 H+2}
$$

$$
H(p)=\frac{1}{p^{2}-1}\left[\frac{p}{\sqrt{p^{2}-1}} \ln \left(p+\sqrt{p^{2}-1}\right)-1\right]
$$

The function $H(p)$ represents the influence of the nanotubes aspect ratio on the critical volume fraction $f_{c}$.

\section{Appendix B - mechanical nanocomposite model}

\section{Voigt- Reuss model}

The maximum tensile modulus $E_{L}$ (i.e. the modulus along the tube direction) thus can be obtained by [39]:

$$
E_{L}=f_{n} E_{n}+\left(1-f_{n}\right) E_{m}
$$

Similarly the lowest tensile modulus $E_{T}$ is expected when all the nanotubes are aligned normal to the tensile load direction [39] as:

$$
\frac{1}{E_{T}}=\frac{f_{n}}{E_{n}}+\frac{1-f_{n}}{E_{m}}
$$

Eqn. (B1) is the Voigt upper bound and Eqn. (B8) gives the Reuss lower bound. They two together give the range of the composite modulus for an arbitrary geometry of fillers.

\section{Hashin-Shritkman bounds}

The model is based on the assumption that the nanocomposite is isotropic and quasi-homogeneous [39]. Regarding to the fact that the stiffness of the carbon nanotube is much greater than that of the epoxy matrix, the H-S bounds taken in this model behaves as shown following [39]:

$$
K=K_{n}+\left(1-f_{n}\right)\left[\frac{1}{K_{n}-K_{m}}+\frac{3 f_{n}}{3 K_{n}+4 G_{f}}\right]^{-1}
$$




$$
\begin{gathered}
G=G_{n}+f_{n}\left[\frac{1}{G_{n}-G_{m}}+\frac{6\left(1-f_{n}\right)\left(K_{m}+2 G_{m}\right)}{5 G_{m}\left(3 K_{m}+4 G_{m}\right)}\right]^{-1} \\
E=\frac{9 K}{1+3 K / G}
\end{gathered}
$$

$K$ denotes bulk modulus and $G$ is shear modulus. The subscripts $n$ and $m$ indicate the properties of nanotubes and matrix respectively. The bulk modulus $K_{f}$ and $K_{m}$ can be obtained from the Young's modulus and Poisson's ratios of CNTs and epoxy matrix as

$$
K_{(f, m)}=\frac{E_{(f, m)}}{3\left(1-2 v_{(f, m)}\right)}
$$

\section{Shear-lag model}

The shear lag model investigated here is combining the rule of mixtures with the Cox model [40]. It takes the geometric parameters of nanotubes into account. The Young's modulus $(E)$ estimation for randomly oriented nanotube-polymer composite can be given as [40]:

$$
\begin{array}{r}
E=\eta_{o} E_{n} f_{n}\left[1-\frac{\tanh (\beta L / 2)}{\beta L / 2}\right]+E_{m}\left(1-f_{n}\right) \\
\beta=\left(\frac{H}{E_{n} \pi r_{0}^{2}}\right)^{1 / 2}, H=\frac{2 \pi G_{m}}{\ln \left(1 / f_{n}{ }^{1 / 2}\right)}
\end{array}
$$

Where $E_{n}$ and $E_{m}$ are the Young's modulus of the matrix and nanotubes respectively, $G_{m}$ denotes the shear modulus of the matrix, $f_{n}$ is the volume fraction of nanotubes in respect to the effective matrix. $L$ is the the average length of nanotubes and $r_{0}$ is the average radius of nanotubes. The parameter $\eta_{o}$ gives corrections for non-unidirectional reinforcements in the matrix. For randomly aligned carbon nanotubes along the three directions $\eta_{o}$ is taken as 0.2 . According to the assumptions, the effective matrix would be isotropic.

\section{Hua-Shi model}

The Hua-Shi approach describes the tensile modulus along the longitudinal and transversal directions as:

$$
\begin{gathered}
E_{L}=E_{m}\left[1-\frac{f_{n}}{\xi}\right]^{-1} \\
E_{T}=E_{m}\left[1-\frac{f_{n}}{4}\left(\frac{1}{\xi}+\frac{3}{\xi+\Lambda}\right)\right]^{-1}
\end{gathered}
$$

Where:

$$
\begin{gathered}
\xi=f_{n}+\frac{E_{m}}{E_{f}-E_{m}}+3\left(1-f_{n}\right)\left[\left(\frac{(1-g) p^{2}-g / 2}{p^{2}-1}\right)\right] \\
\Lambda=\left(1-f_{n}\right)\left[\frac{3\left(p^{2}+0.25\right) g-2 p^{2}}{p^{2}-1}\right] \\
g=\frac{p}{\left(p^{2}-1\right)^{3 / 2}}\left[p \sqrt{p^{2}-1}-\cosh ^{-1} p\right]
\end{gathered}
$$




\section{Appendix C - Dielectric model of the unidirectional ply}

In a unidirectional composite the electrons travel either through the fibers or through the conductive matrix. Fibres and matrix can be considered as parallel circuits Thus the overall resistance of the composite can be obtained from the expression:

$$
\frac{1}{R_{C}}=\frac{1}{R_{f 1}}+\frac{1}{R_{f 2}}+\cdots+\frac{1}{R_{f n}}+\frac{1}{R_{m}}
$$

Also we know that

$$
R=\rho \frac{l}{A}=\frac{1}{\sigma} \frac{l}{A}
$$

Substituting Eqn(22) relationship into Eqn(21), we have

$$
\sigma_{C} A_{C}=\sum \sigma_{f} A_{f i}+\sigma_{m} A_{m}
$$

Then

$$
\begin{aligned}
\sigma_{C} & =\sigma_{f} \frac{\sum A_{f i}}{A_{C}}+\sigma_{m} \frac{A_{m}}{A_{C}} \\
& =\sigma_{f} f_{C F}+\sigma_{m} f_{m}
\end{aligned}
$$

\section{Appendix D - Dielectric composite laminate model}

Following [51], the angle between the fiber orientation (denoted as 1) and the electric field vector (denoted as $\mathrm{x}$ ) is $\theta$. For plies aligned along the electric field $\left(\theta=0^{\circ}\right)$ the conductivity equals the one of the unidirectional ply. For plies aligned normally to the electric field $\left(\theta=90^{\circ}\right.$ ), the current travels by transverse conductivity. For plies with other orientation angles, the conductivities can be calculated simply by transforming the conductivity vector (containing conductivity in fiber direction and the transverse direction) into the electric field direction and the normal direction by the following transformation matrix [49]:

$$
\begin{gathered}
{[\Sigma]=\left[\begin{array}{cc}
\cos \theta & \sin \theta \\
-\sin \theta & \cos \theta
\end{array}\right]\left[\begin{array}{cc}
\sigma_{1} & 0 \\
0 & \sigma_{2}
\end{array}\right]\left[\begin{array}{cc}
\cos \theta & -\sin \theta \\
\sin \theta & \cos \theta
\end{array}\right],} \\
\sigma_{x}=\Sigma_{11}, \\
\sigma_{y}=\Sigma_{22},
\end{gathered}
$$

By assuming an ideal uniform distribution of the current density along the conducting path, the laminate stack is modeled as an ensemble of parallel resistors. The overall effective in-plane resistance of the composite $R_{C \|}$ is evaluated by

$$
\frac{1}{R_{C \|}}=\sum_{i=1}^{N} \frac{1}{R_{p i \|}}
$$

Where $R_{p i \|}$ represents the effective resistance of the $i^{\text {th }}$ ply, and $N$ is the number of plies in the composite. The resistance in general is defined as:

$$
R=\rho \frac{l}{A}=\frac{1}{\sigma} \frac{l}{w h}
$$

Where $w$ and $h$ denote the width and thickness of the composite panel. After manipulation Equation (D2) provides the expression of the effective in-plane conductivity of the composite: 


$$
\sigma_{C \|}=\sum_{i=1}^{N} \sigma_{p i \|} h_{p i}
$$

Where $\sigma_{p i \|}$ represents the effective in-plane conductivity of the $\mathrm{i}^{\text {th }}$ ply, and $h_{p i}$ represents the thickness of the $\mathrm{i}^{\text {th }}$ ply. For a perfectly bonded laminate the current conducting through-the-thickness path is composed by the thickness of the plies in series. The effective conductivity in this direction is modeled as series resistors:

$$
R_{C \perp}=\sum_{i=1}^{N} R_{p i \perp}=\sum_{i=1}^{N} \frac{1}{\sigma_{p i \perp}} \frac{h_{p i}}{w l}
$$

Similar to the in-plane conductivity, one can easily obtain the effective through-thickness conductivity as:

$$
\sigma_{C \perp}=\sum_{i=1}^{N} \frac{\sigma_{p i \perp}}{h_{p i}}
$$

